\title{
Predicates of Personal Taste and Pancake Sentences in Brazilian Portuguese and French
}

\author{
Fabienne Martin, Janayna Carvalho and Artemis Alexiadou
}

\section{$1 \quad$ Introduction}

In several languages, for instance Mainland Scandinavian, Hebrew, Brazilian Portuguese, and French, certain intriguing agreement and interpretational patterns are found in copular constructions, as shown in (1), from Wechsler (2013), (2) and (3) from Roy and Shlonsky (2019), and (4a) from Rodrigues and Foltran $(2015):^{1}$

(1) Swedish
Pannkakor är gott.

pancake.PL be.3sG.PRS good.N.SG

'Situations involving pancakes are good (e.g., eating pancakes).'

(2) Hebrew

studentim ce'irim ze méanyen.

student.M.PL young.M.PL be.M.SG interesting.M.SG

'Teaching/talking to/etc. young students is interesting.'

(3) French

Les/des enfants, c'est chouette.

the.PL/ PA.PL child.M.PL DEM=be.3sG.PRS fun.M.SG

'Doing something with children (having them, playing with them, raising them, and so on) is cool/fun.'

(4) Brazilian Portuguese
a. Crianças é
divertido.
child.F.PL be.3sG.PRs fun.M.sG
'Playing with children/taking care of them ... is fun.' (our translation)

\footnotetext{
1 Translations are provided from the authors, except when indicated.

(C) FABIENNE MARTin, JANAYNA CARVAlHo AND ARTEMis AlEXiAdou, 
b. Estudantes é interessante.

student.M.PL be.3SG.PRS interesting.M.SG

'Doing something with students (e.g., supervising them) is interesting.'

The sentences in (1)-(4) show similar syntactic and semantic properties. Firstly, the predicate appears in unmarked form for gender and number, and this correlates with a special reading for the subject; in particular, the bare NP or the DP subject does not receive its literal meaning. ${ }^{2}$ We argue that the nominal expression is rather understood as referring to a type of events involving the original referent as a theme. We call this reading of the subject the event type reading. Following Wechsler (2013), we call sentences (1)-(4) pancake sentences, and their subjects will be labelled pancake subjects. Inspired by previous work of Piñón (2016) on a subclass of evaluative predicates, we propose that the subject of these sentences stands for a more complex, partially covert semantic structure denoting an event type, while the adjectival phrase predicates a (second-order) property over this event type.

This paper intends to offer an analysis of syntactic and semantic aspects of pancake sentences, having Brazilian Portuguese and French as its focus. Comparing these two languages is interesting because they differ in the structures they adopt to achieve the same interpretation.

The pattern in (5) summarizes the main ingredients of pancake sentences cross-linguistically. In all languages, including Brazilian Portuguese and French, the subject position is filled with a nominal expression which is individual-denoting in its literal meaning, as well as a copula and an adjective. The parentheses capture some cross-linguistic differences. While Brazilian Portuguese only allows bare NPs in this construction, French requires DPs in subject position (as it does in most argumental positions). Additionally, in most cases, the nominal expression is left-dislocated in French, and serves as the antecedent of the anaphoric demonstrative $c e$, whereas Brazilian Portuguese pancake sentences typically do not license left-dislocation nor demonstrative pronouns. ${ }^{3}$

2 Romance languages vary as to whether they allow bare nouns and/or nominals with a "partitive article" in subject positions; for more details on the issue, see Giusti (this volume). Strobel and Glaser (this volume) discuss subjects with genitive case in Germanic, often corresponding to bare nouns in English.

3 The demonstrative pronoun $c e$ and left dislocation are not compulsory with numerals in the subject position, nor with a VP in the same position, see Sections 4 and 6. 
(5) Individual-denoting nominal expression (DP/NP)-(neuter demonstrative pronoun)-copula-adjective.

Importantly, pancake sentences in all languages mentioned above have counterparts with full agreement, where the bare NP or DP in subject position receives its literal (individual-denoting) interpretation. The difference between (4b) and (6a) illustrates this. Sentence (4b) is true if event types involving young students as theme are generally interesting (e.g., supervising them is interesting), but as Greenberg (2008) observes about a similar contrast in Hebrew, this may be true if very few or even no young students involved in these event types are interesting. By contrast, (6a) necessarily attributes the property of being interesting to the individuals denoted by the noun in subject position. ${ }^{4}$

(6) Brazilian Portuguese

a. Estudantes são interessantes.

student.M.PL be.3PL.PRS interesting.M.PL

'Students are generally interesting.' NOT: 'Event types involving students as theme (supervising them, etc.) are generally interesting.'

b. Estudante é interessante.

student.M.SG be.3SG.PRS interesting.M.SG

'Students are generally interesting' or 'Event types involving students as theme (supervising them, etc.) are generally interesting.'

In languages such as Brazilian Portuguese, the bare NP in pancake sentences can be either singular or plural (as usually the case for subjects of generic sentences in such languages). When the bare subject is formally plural and the adjective singular (as in (4a)), or when the bare subject is singular and feminine and the adjective singular and masculine (as in (7a) below), we clearly have a surface mismatch, and as a result only the event type reading obtains. By contrast, when the bare subject is formally singular and masculine, it is ambiguous between an 'event type' and an 'individual kind' reading if the right type of adjective is used, see (6b). On the individual kind reading, the adjective agrees in gender and number with the nominal expression (masculine singular). But on the event type reading obtained in a pancake sentence, the adjective does

4 How (non)-individuated reference may affect the internal structure of noun phrases in Romance is explored in Gerards and Stark (this volume); (non)-individuation also plays a role in the analysis of Schurr (this volume). 
not agree with the nominal expression, and rather receives default agreement, which is masculine and singular in Brazilian Portuguese.

As the translation of (6a) already suggests, the subject cannot be reinterpreted as its pancake counterpart in copular sentences with full agreement. That is, only non-agreeing constructions may have pancake subjects (see Rodrigues and Fortran 2015 for similar observations on Brazilian Portuguese). The contrast between (7)-(8) illustrates this point: while sentences in (7) make perfect sense (because an event type involving pancakes can be friendly), sentences in (8) are non-sensical (or funny), for they necessarily attribute friendliness to pancakes themselves. The contrasts in (9)-(12) are similar. Raising children may be expensive, but it is weird to attribute a financial value to children. Likewise, (12) oddly states that domestic animals are in general complicated, while (11) asserts that having domestic animals, caring for them, etc. is complicated.

(7) Brazilian Portuguese/ French
a. Panqueca é
amigável.

pancake.F.SG be.3SG.PRs friendly.M.SG

b. Les/des crêpes, c'est convivial. the.PL/ PA.PL pancake.F.PL DEM=be.3SG.PRS friendly.M.SG 'Pancakes will make a convivial/easy/warm evening/ Pancakes, that's convivial.'

(8)
a. \#Panquecas são
amigáveis.

pancake.F.PL be.3PL.PRS friendly.M.PL
b. \#Les crêpes
sont
conviviales.
the.PL pancake.F.PL be.3PL.PRS friendly.F.PL
'(The) pancakes are friendly.'

(9)
a. Criança é
caro.
child.F.SG be.3SG.PRS expensive.M.SG
b. Les/des enfants, c'est cher.
the.PL/ PA.PL child.M.PL DEM=be.3SG.PRS expensive.M.SG 'Having children, raising them, etc. is expensive.'

$\begin{aligned} \text { (10) a. \#Criança } & \text { é } \\ \text { child.F.SG be.3sG.PRs } & \text { expensive.F.SG }\end{aligned}$ 
b. \#Les enfants sont chers.

the.PL child.M.PL be.3PL.PRS expensive.M.PL

'(The) children are expensive.'

(11) a. Animais domésticos é complicado.

animal.M.PL domestic.M.PL be.3SG.PRs complicated.M.sG

b. Les/des animaux de compagnie, c'est

the.PL/ PA.PL animal.M.PL of company DEM=be.3SG.PRS compliqué.

complicated.M.sG

'Having domestic animals, caring for them, etc. is complicated.'

(12) a. Animais domésticos são complicados.

animal.M.PL domestic.M.PL be.3PL.PRS complicated.M.PL

b. Les animaux de compagnie sont compliqués.

the.PL animal.M.PL of company be.3PL.PRS complicated.M.PL

'Domestic animals are complicated.'

As the French examples above illustrate, the D P used in this type of sentences is systematically dislocated. Dislocation alone does not suffice to obtain the event type reading; the choice of the demonstrative pronoun ce unmarked in gender and number is a necessary ingredient for the reinterpretation of the dislocated DP. A dislocated structure with a pronoun inflected in gender and number such as elles does not license the event type reading; for instance, $(13 \mathrm{a}-\mathrm{b})$ raise the same anomaly as (8) and (10).

(13) French

a. \#Les crêpes, elles sont conviviales.

the.PL pancake.F.PL they.NOM.F.PL be.3PL.PRS friendly.F.PL

'(The) pancakes, they are friendly.'

b. \#Les enfants, ils sont chers.

the.PL child.M.PL they.NOM.M.PL be.3PL.PRS expensive.M.PL

'(The) children, they are expensive.'

Following many other authors, we assume that pancake subjects stand for a larger and partly covert semantic structure. Building on Heller (1999), Greenberg (2008), and Wechsler (2013), we argue that this covert semantic structure 
is obtained through a reinterpretation mechanism of the nominal expression, similar to Pustejovsky's (1995) mechanism of logical metonymy, where a part stands for a whole. For instance, in start the book, the book is not understood under its literal individual-denoting entity, but rather interpreted as standing for a whole - an event of reading, writing ... the book-of which the book forms a proper part only. The question of whether and how this covert structure is realized in the syntax is not addressed in this paper (see Josefsson 2009 on the idea that the covert structure has the syntactic properties of a verbal projection, which is syntactically active although not pronounced, and see Wechsler 2013 for some counter-arguments).

As Danon (2012) observes, pancake sentences raise important questions for the syntax of noun phrases and the theory of agreement, since the lack of agreement correlates with a special semantics. One puzzle, however, is that this correlation is optional for some languages, where the lack of agreement only allows, but does not automatically trigger, the event type reading of the subject. This has already been noted by Greenberg (2008) for Hebrew, and we will show that it is also the case in French. In French (as in Hebrew), pancake sentences therefore form a proper subset of non-agreeing copular sentences (i.e., copular sentences with no agreement between the gender/number feature of the first subject and the adjective). ${ }^{5}$ In contrast, in other languages, the special event type semantics is compulsory in absence of agreement. We will argue that this is the case in Brazilian Portuguese, and we aim to explain this cross-linguistic difference.

We propose that in Brazilian Portuguese and in French, as apparently is also the case for other languages, it is the agreement feature mismatch which triggers the reinterpretation mechanism of the nominal expression. Under the pancake reading, the subject stands for a non-overt semantic structure. Precisely because this semantic structure is covert, it lacks agreement features, which explains the agreement feature mismatch, as proposed by Greenberg (2008). However, the exact output of the reinterpretation mechanism (and the meaning of the covert semantic structure the nominal expression stands for) depends on the building blocks of a non-agreeing copular sentence, which are different in Brazilian Portuguese and French. These differences will explain why French non-agreeing copular sentences may have more than one meaning and are thus not necessarily pancake sentences.

5 Thus for us, the event type reading is a defining and necessary property of pancake sentences. In contrast, Wechsler (2013) uses this label for a broader kind of non-agreeing copular sentences, including sentences where the subject receives a kind interpretation (that Wechsler calls 'kind-type pancake sentences'). 
An overlooked common property of pancake sentences is that they are all built with evaluative adjectives of a certain type, of which funny, interesting or complicated are typical examples. In particular, we observe that object experiencer adjectives (for instance, adjectives derived from object experiencer psych-verbs, such as surprising, fascinating, depressing), better known as predicates of personal taste, are systematically acceptable in pancake sentences, although if and only if they can predicate a property of an event type. This condition is satisfied when the adjective accepts an infinitival VP as a subject. As Bylinina (2014) already observed, not all predicates of personal taste may host such a subject; compare eating pancakes is depressing/*tasty. Also, factual adjectives (e.g., green), evaluative adjectives that cannot have infinitival subjects (e.g., quiet, anxious, tasty), or evaluative adjectives that can have such subjects but are not experiencer predicates (e.g., lazy, faithful, smart) generally cannot be used in pancake sentences. We think that the selection of adjectives in these sentences reveals something crucial about their semantics and helps understand why pancake subjects are interpreted the way they are. The details of the semantic analysis have to differ for Brazilian Portuguese and French, however, because of aspectual differences between the pancake sentences in these languages. In particular, while pancake sentences must be generic in Brazilian Portuguese, they may also be episodic in French (for further discussion of generic readings and episodic sentences, see Stark and Gerards this volume and Giusti this volume).

This paper is organized as follows. In Section 2, we offer a typology of adjectives in non-agreeing copular sentences across languages. Building on Bylinina's $(2014,2017)$ typology of evaluative predicates, we identify the subtypes of these adjectives inducing the event type reading characteristic of pancake sentences. As we will see, only evaluative adjectives that (i) may predicate a property over an event type and (ii) are predicates of personal taste/object experiencer adjectives are felicitous in Brazilian Portuguese and French pancake sentences, which we take to support our proposal. We walk through our semantic analysis for pancake sentences in Brazilian Portuguese and French in Section 3. We first spell-out its main ingredients in Section 3.1, turning to episodic pancake sentences in Section 3.2, and then to generic ones in Section 3.3. Section 3.4 accounts for the absence of entailment between a pancake sentence and its counterpart with full agreement. In Section 4, we address the question of why the pancake interpretation in non-agreeing copular sentences is only optional in French but compulsory in Brazilian Portuguese. Section 5 raises the question of whether pancake sentences exist in Germanic languages such as English and German. 


\section{$2 \quad$ Typology of Adjectives in Non-agreeing Copular Sentences}

\subsection{Factual vs. Evaluative Adjectives}

As already pointed out by De Conto $(2016,2018)$, adjectives used in pancake sentences are systematically evaluative. We believe that this is not an accident, and that the evaluative adjective present in this type of sentences is the main source of the event type interpretation of the subject.

As is well-known, one of the specificities of evaluative adjectives is that they can be predicated either of individuals or of eventualities. Some of them can also be predicated of more abstract objects such as states of affairs or propositions (Kertz 2009; Landau 2009 among others), and, crucially, event types (Piñón 2016). On this point, they differ from, for instance, factual adjectives such as adjectives of color, which can be predicated over individuals only. We call such adjectives i-predicates.

Interestingly, however, it is not the case that i-predicates are banned from non-agreeing copular sentences altogether. French, for instance, allows them. When built with i-predicates, non-agreeing copular sentences unsurprisingly do not induce an event type reading for their subject as was the case in (1)-(4) and are therefore not pancake sentences in the typology adopted here. Take for instance the French sentence (14), from Roy and Shlonsky (2019). Clearly, (14) does not mean that doing something involving vegetables is green, and the same point can be made about (15).

(14) French

Les/des légumes, c'est vert.

the.PL/ PA.PL vegetable.M.PL DEM=be.3sG.PRS green.M.SG

'Vegetables are green.' Nот:\#'Doing something with vegetables is green.'

(15) Les/des tables, c'est droit.

the.PL/ PA.PL table.F.PL DEM=be.3SG.PRs straight.M.SG

'Tables are straight.' Nот:\#'Doing something with tables is straight.'

In contrast, Brazilian Portuguese disallows adjectives of color in non-agreeing copular sentences altogether, see (16)-(17). Note that this is also not possible if the nominal expression is dislocated and a demonstrative inserted, see (18).

(16) Brazilian Portuguese

*Maçã é vermelho.

apple.F.sG be.3sG.PRS red.M.sG

Intended: 'Apples are red.' 
(17) *Mesa éreto.

table.F.sG be.3SG.PRs straight.M.sG

Intended: 'Tables are straight.'

(18)
*Maçã, isso é vermelho.
apple.F.SG DEM be.3SG.PRS red.M.SG
Intended: 'Apples, that's red.'

In summary, French allows i-predicates in non-agreeing copular sentences, which, however, are not pancake sentences with these adjectives. In contrast, Brazilian Portuguese seems to only allow evaluative adjectives in non-agreeing copular sentences, and those must be pancake sentences.

\subsection{Not All Evaluative Adjectives Are 'Pancake' Adjectives}

Pancake sentences cannot be built with any evaluative adjective, though. In order to induce the event type reading, the evaluative adjective must fulfill two conditions. Firstly, it should be able to predicate over an event type. Adjectives used in (1)-(4) are of this kind. Evidence for this is that one can explicitly apply these adjectives to an infinitive denoting an event type, see for instance (19)-(20) (different event types are also considered in Ihsane's analysis in her contribution to this volume of plural complements with a "partitive article" in French).

(19) French

Jouer avec des enfants est marrant/anxiogène. play.INF with PA.PL child.M.PL is funny.M.SG/stressful.M.sG 'Playing with children is funny/stressful.'

(20) Brazilian Portuguese

Brincar com criança é engraçado/estressante.

play.INF with child.F.sG is funny.M.sG/stressful.M.sG

'Playing with children is funny/stressful.'

This, however, is not possible with all evaluative adjectives. Subject experiencer adjectives, for instance anxious, or fearful, obviously cannot predicate over an event type, since their subject must refer to an experiencer, see (21)-(22). Also, behavior-related adjectives such as lazy cannot be predicated over event types either, see (23)-(24). 
(21) French

\#Jouer avec des tigres est anxieux/craintif. play.INF with PA.PL tiger.M.PL is anxious.M.SG/fearful.M.SG \#'Playing with children is anxious/fearful.'

(22) Brazilian Portuguese

\#Brincar com tigre é ansioso/medroso.

play.INF with tiger.M.SG be.3SG.PRS anxious.M.sG/fearful.M.sG

\#'Playing with tiger is anxious/fearful.'

(23) French

\#Aller en voiture au travail est paresseux. go.INF in car to.the work be.3SG.PRs lazy.M.SG Intended: 'Going to work by car is lazy.'

(24) Brazilian Portuguese

\#Ir de carro pro trabalho é preguiçoso.

go.INF of car to.the work be.3sG.PRs lazy.M.sG

Intended: 'Going to work by car is lazy.'

It is important to note that adjectives like anxious or lazy can be predicated over events, however. For instance, assuming that a game is an event-denoting noun, the fact that (25)-(28) are acceptable suggests that the French and Brazilian Portuguese counterparts of anxious or lazy can be predicated over events, although, as we just saw, they cannot be predicated over event types.

(25) French

Son jeu était craintif/paresseux.

his game be.3sG.IMPF fearful.M.sG/lazy.M.sG

'His way to play/game was fearful/lazy.'

(26) Le trypanosome a des mouvements paresseux.

the trypanosoma have.3SG.PRS PA.PL movements lazy.M.PL

'The Trypanosoma has lazy movements.'

(27) Brazilian Portuguese

$O$ jeito dele era medroso/preguiçoso.

the way.M.sG of.his be.3sG.IMPF fearful.M.sG/lazy.M.sG

'His way to play/game was fearful/lazy.' 


\section{(28) A tripanossoma tem movimentos preguiçosos. \\ the trypanosoma have.sG.PRs movement.M.PL lazy.M.PL \\ 'The Trypanosoma has lazy movements.'}

Similarly, in (29), the adverbial derived from paresseux arguably has the semantics characteristic of run-of-the-mill manner adverbials, which are standardly analyzed as predicates of events (see, e.g., Parsons 1990).

\section{(29) French}

\section{La neige tombe paresseusement sur le sol.}

the snow fall.3sG.PRs lazily on the ground

'Snow is falling lazily on the ground.'

That some adjectives such as lazy can be predicated over events, but nevertheless not be licensed in pancake sentences is interesting, because this indirectly suggests that the pancake adjective is not simply interpreted as predicated over events in this type of sentences. Inspired by Piñón (2016), we propose that the pancake adjective rather denotes a second-order property predicated over an event type (denoted by the covert semantic structure for which the nominal expression stands for).

A second property common to all evaluative predicates licensed in pancake sentences is that they are all (object) experiencer predicates projecting an experiencer argument. ${ }^{6}$ It is not the case that all evaluative predicates are experiencer predicates. Lazy or smart are not experiencer predicates; interesting or fun are. All evaluative predicates 1) can be embedded under subjective attitude verbs such as find or consider, 2) have their content depending on a judge parameter (the person who decides on matters of taste) and 3) give rise to subjective (or faultless) disagreement (Lasersohn 2005 a.m.o.). However, Bylinina (2017) shows that among evaluative predicates, only experiencer predicates may have an extra 'experiencer' argument, which is expressed in a to- or for-PP for object experiencer predicates. For instance, the evaluative adjectives lazy or smart, which are not experiencer predicates, do not take a to-/for-PP, while interesting or fun do, see (30). ${ }^{7}$

6 As will see later through the examples (88), French also allows non-copular sentences to have a pancake flavour, and interestingly, they also involve experiencer predicates.

7 When behavior-related adjectives can host a for-/to-PP, this PP is associated to the beneficiary rather than experiencer role. For instance, John is generous to Mary is grammatical, but this sentence does not entail that Mary experiences something; in fact, Mary may be completely unaware of John's generosity, even if she benefits from it. 
(30) a. This book is interesting for/ to me. (Bylinina 2017)

b. ?? Mary is smart for/ to me. (ibid.)

Thus, only evaluative experiencer predicates have an experiencer argument beyond a judge parameter. Although the experiencer argument and the judge parameter form different ingredients of the semantics of experiencer predicates, they are intimately connected. As Bylinina observes, they have to be set to the same value for the evaluative statement to be felicitous. Sentence (31a) illustrates this: the subject of find gives the value of the judge parameter, and the for-/to-PP refers to the experiencer. Given that (31a) indicates that they are not set to the same value, infelicity arises (whereas (31b) is acceptable).

(31) a. \#I find this fun for John.

b. I find this fun for me.

To capture this relation, Bylinina (2017) proposes a "judge=experiencer requirement", i.e. the requirement that a statement about someone's internal state can be made only if the judge parameter is set to the same value as the experiencer of this state. She formulates this requirement as a presupposition (see (34a-b) i) below).

On the basis of Japanese and Hungarian data, Bylinina $(2014,2017)$ argues that the presence of an extra experiencer argument systematically correlates with reference to an experience event as part of the predicate semantics. This experience event will play a crucial role in the semantics of pancake sentences (see Section 3). Reference to an experience event is obvious for subject experiencer adjectives such as afraid or worried. But Bylinina argues that the subjectivity of object experiencer predicates such as interesting, fun or tasty also has its source in an experience event they semantically refer to. However, object experiencer predicates vary in the type of experience event they denote. In the case of tasty or delicious, Bylinina argues that the experience event is a tasting event of the stimulus (the external argument of the predicate) by the experiencer. This accounts for the oddity of (32a) (first observed by Stephenson 2007), which strongly suggests that Sam tasted the cat food.

(32) a. \#Sam finds the cat food tasty. (Stephenson 2007, 98)

b. The ride was interesting/fun.

In the case of fun or interesting, Bylinina argues that the experience event is an event which may be described by the external argument of the predicate, for instance the riding event in $\left(3^{2 b}\right)$. 
This distinction between the two subtypes of object experiencer predicates is relevant for us, too. As also observed by Bylinina (2014), only adjectives such as interesting may predicate over event types, see $\left(33^{\mathrm{a}}-\mathrm{c}\right)$. Adjectives such as tasty cannot do so. For this reason, they do not form felicitous pancake sentences, neither in English, nor in Brazilian Portuguese, as will be shown below.

(33) a. To eat pancakes is fun.

b. *To eat pancakes is tasty.

c. Brazilian Portuguese

*Comer panqueca é saboroso/delicioso.

eat.INF pancake.F.SG be.3SG.PRS delicious.M.SG

Bylinina proposes a slightly different semantics for the two subtypes of experiencer adjectives which captures this difference, see (34a-b), from Bylinina $(2017,327)$ (she has a state variable $s$ that we turn to an event variable $e$ ). In (34), the interpretation function $\llbracket \rrbracket$ has as parameters a context $c$, an assignment function $g$, a world $w$, a time $t$ and a judge $j$, with $j$ identified to the speaker $S p$ in absence of judge-shifting expression such as find. In prose, according to her analysis, this pancake is tasty states that there is a tasting event $e$ experienced by the experiencer (assumed to be syntactically projected as a null pronoun pro when implicit, see Epstein 1984) and which has this pancake as stimulus, and such that $e$ gives rise to a percept on the TASTE scale greater than some standard degree $d_{s t}$ according to the judge/speaker $S p$ (and required to be identified with the experiencer). In contrast, this ride is fun states that there is a riding event $e$ experienced by pro and such that $e$ gives rise to a percept on the FUN scale greater than the standard degree $d_{s p}^{s t}$ according to $S p$ (again identified with the experiencer). Pronouns come with an index, and the assignment function $g$ returns an individual for this index.

(34) a. 【This cake is tasty pro $_{8} \rrbracket^{c, g, w, t, S p}=$
i) defined iff $g(8)=S p$
ii) $\exists e[\operatorname{taste}(e) \wedge$ experiencer $(e, S p) \wedge \operatorname{stimulus}(e$, this cake $) \wedge$ $\operatorname{TASTE}(e)>d_{s p}^{s t}$ for $S p$ at $t$ in $\left.w\right]$;

b. 【The ride was fun pro $_{9} \rrbracket^{c, g, w, t, S p}=$

i) defined iff $g(9)=S p$

ii) $\exists e\left[\operatorname{ride}(e) \wedge \operatorname{experiencer}(e, S p) \wedge \mathrm{FUN}(e)>d_{s p}^{s t}\right.$ for $S p$ at $t$ in $\left.w\right]$

c. Yesterday, the students were interesting. 
Let us underline that Bylinina's understanding of what it means to be an experiencer is rather different from what is generally understood in the literature on psych-predicates. For her, being an experiencer of an event $e$ projected by a predicate of personal taste means to directly participate to $e$, as a taster, a rider, or whatever. This is because with others such as, e.g., Stephenson (2007) or Pearson (2013), she assumes that predicates of personal taste impose a "direct sensory experience of the relevant kind on the basis of which to judge whether $x$ is $P$ " (Pearson 2013). Thus, the experiencer must be a 'first hand participant' of the experience event encoded by predicates of personal taste. And ultimately, an experiencer of $e$ can also be the agent of $e$, which will be also relevant for us.

We agree with Bylinina that predicates such as fun systematically refer to a (direct) experience event. We would like to add that this event is not systematically described by the external argument of these adjectives. In particular, with individual-denoting subjects as in (34c), we take the external argument to be a stimulus rather than an event. The property of the experience event remains then implicit. We come back to the semantics of fun-adjectives used as predicates of individuals in Section 3. 4.

In summary, we have distinguished five types of evaluative adjectives, see a)-e) below (note that for obvious reasons, the sixth possible type is not instantiated, since no subject experiencer predicate can have an event type as their first argument). ${ }^{8}$

(35) a. lazy-adjectives:

not predicates of event types no experiencer argument

b. generous-adjectives:

predicates of event types no experiencer argument

c. worried-adjectives:

not predicates of event types subject experiencer argument

d. tasty-adjectives:

not predicates of event types object experiencer argument

e. interesting-adjectives:

predicates of event types

object experiencer argument

The generalization we observe is that apart from some few exceptions, ${ }^{9}$ among evaluative adjectives, only predicates of personal taste of type e) are licensed

8 Note that in English, lazy may be predicated of an event type, while it is not the case of the French and Brazilian Portuguese counterpart of this adjective, as our examples (23)-(24) show.

9 The adjective expensive is one exception. It is evaluative, and it is not a causative experiencer 
in pancake sentences. In other words, only evaluative adjectives that may predicate over an event type and have an object experiencer argument are felicitous 'pancake' adjectives. Most -ing adjectives derived from object experiencer psychological verbs-interesting, surprising, depressing, fascinating ...- are thus pancake adjectives.

A first illustration of this generalization is that Brazilian Portuguese pancake sentences built with adjectives that cannot have an infinitival subject are all ungrammatical, see $(36)$.

(36) Brazilian Portuguese
a. ${ }^{*}$ Mulher é
ansioso/medroso/preguiçoso.
woman.F.SG be.3SG.PRS anxious/fearful/lazy.M.SG
$\begin{array}{ll}\text { b. }{ }^{*} \text { Panqueca é } & \text { saboroso. } \\ \text { pancake.F.SG } & \text { be.3SG.PRS tasty.M.SG }\end{array}$

Secondly, the sentences in (37a)-(38a), built with adjectives of type b) that may have an infinitival subject (see $(37 \mathrm{~b})-(38 \mathrm{~b}))$, but are not experiencer predicates, are ungrammatical as well.

(37) Brazilian Portuguese

a. *riança é generoso. child.F.SG be.3SG.PRS generous.M.SG

Intended: 'Playing with children/caring for them ... is generous.'

b. Cuidar de criança é generoso.

take.care.INF of child.F.SG be.3SG.PRS generous.M.SG

'Caring for children is generous.'

(38) a. *Amigo é leal.

friend.M.SG be.3SG.PRs faithful.M.sG

Intended: 'Doing something involving friends is faithful.'

b. Apoiar um amigo doente é leal. support.INF a friend.M.SG sick be.3SG.PRS faithful.M.SG 'Supporting a sick friend is faithful.'

object adjective, but it is acceptable in pancake sentences (see examples in the introduction). Other potential exceptions are modal adjectives such as important, forbidden, necessary. We leave this problem aside for now. 
French confirms the generalization proposed above too, although in a different way. In French, non-agreeing copular sentences built with an adjective of type e) (interesting) can all be pancake sentences, see, for instance, (3) in Section 1. In contrast with Brazilian Portuguese, however, non-agreeing copular sentences built with adjectives of classes a) to d) are all acceptable. However, they are not pancake sentences, see (39)-(40).

(39) French

Les enfants, c'est anxieux/craintif/paresseux.

the.PL child.M.PL DEM=be.3SG.PRS anxious/fearful/lazy.M.SG

'Children are (in general/always) anxious/fearful/lazy'. Noт:\#'Dealing, talking ... with children is anxious/fearful/lazy'

(40) Les enfants, c'est généreux/loyal.

the.PL child.M.PL DEM=be.3SG.PRS generous/faithful.M.SG

'Children are (in general/always) generous/faithful.' мот:\#'Dealing, talking ... with children is generous/faithful.'

\subsection{Alternating Adjectives}

As is well-known, a subset of experiencer adjectives, such as sad or curious, can project their experiencer argument either as a subject or as a for-/to-object, which may remain implicit, see Pustejovsky (1995), Landau (2009), Ramchand (2018), a.o., cf. (41).

(41) These women are sad.

a. These women EXP $_{\text {feel sad. }}$

(subject experiencer use)

b. The women are sad (for $\left.\mathrm{X}_{\mathrm{EXP}}\right)$.

(object experiencer use)

For obvious reasons, the object experiencer use is automatically selected when the external argument is non-animate (this book is sad/curious).

We proposed above that evaluative adjectives are acceptable in pancake sentences only if they are object experiencer adjectives. Given this structural property, we therefore expect alternating adjectives such as sad to be exclusively used as object experiencer predicates in pancake sentences. Brazilian Portuguese confirms this prediction. For instance, in non-agreeing copular sentences, triste 'sad' can only be used as an object experiencer adjective (although it then conveys toughness rather than sadness), see (42). The same point can be made about curioso 'curious', see (43). 
(42) Brazilian Portuguese

Criança é triste.

child.F.s be.3SG.PRs sad.M.sG

'Dealing with children, etc. is generally tough.' (object experiencer use) NOT: 'Children are generally sad.' $\quad$ (subject experiencer use)

(43) Mulher é curioso.

woman.F.PL be.3SG.PRS curious.M.SG

'Dealing with women is generally curious/strange.' (object experiencer use)

NOT: 'Women are generally curious.'

(subject experiencer use)

In French, both readings are available in non-agreeing copular sentences, but the pancake interpretation only arises when the adjective is used as an object experiencer adjective, see, for instance, (44).

(44) French

a. Les enfants, c'est triste.

the.PL child.M.PL DEM=be.3SG.PRS sad.M.SG

'Dealing with children is sad.'

(object experiencer use)

'Children are generally sad.' (subject experiencer use)

b. Les femmes, c'est curieux.

the.PL woman.F.PL DEM=be.3SG.PRS curious.M.SG

'Dealing with women is curious/strange.' (object experiencer use)

'Women are generally curious.' (subject experiencer use)

\section{$3 \quad$ Pancake Semantics}

\subsection{Main Ingredients}

The semantics we attribute to the pancake subject on one hand, and to the adjectival phrase on the other, is inspired by Piñón's (2016) analysis of behaviorrelated adjectives such as generous. Similarly to adjectives such as friendly or funny, behavior-related adjectives can have a gerund or an infinitive as subject, see (45).

(45) To donate/donating 300 euros to the museum was generous of Rebecca. 
One of Piñon's core ideas is that in such sentences, the infinitive expresses a property denoting a type of behavior $B$, and the adjective is predicated of this behavior type $B$. Thus, the meaning of the evaluative adjective in (45) is a second-order property predicated of the (first-order) property denoting a type of behavior $B$, see the lexical core of generous in (46a). (46b) is one of the representations Piñón attributes to generous (adopting the semantic roles from FrameNet). Sentence (45) receives the (simplified) semantic representation (47).

(46) a. Lexical core of generous: (Piñón 2016) $\lambda B$.generous $(\lambda e . B(e))$ (behavior type $B$ is generous)

b. A semantic representation of generous $\lambda B \lambda x \lambda$ e.resource-controller $(e, x) \wedge B(e, x) \wedge \operatorname{generous}\left(\lambda e^{\prime} . B\left(e^{\prime}, x\right)\right)$

(47) (Simplified) analysis of (45) (Piñón 2016)

$\lambda e$.resource-controller $(e$, rebecca $) \wedge$ donate-3oo-euros-to-the-muse$\operatorname{um}(e, x) \wedge$ generous $\left(\lambda e^{\prime}\right.$.donate-3oo-euros-to-the-museum $\left(e^{\prime}\right.$, rebecca))

The behavior type $B$ can be left implicit, as in (48), which is then translated as in (49).

(48) Rebecca was generous (yesterday).

(49) $\lambda e$.resource-controller $(e$, rebecca $) \wedge B(e, x) \wedge \operatorname{generous}\left(\lambda e^{\prime} \cdot B\left(e^{\prime}\right.\right.$, rebecca))

In favour of this analysis, Piñón notes that in (45), generous appears to be equivalent to do something generous. According to a potential competing analysis, the adjective generous on the use illustrated in (45) is represented as a first order property of events, see (50a). On this view, (45) would be analyzed as in $(5 \mathrm{ob})$.

(50) a. An alternative representation of generous $\lambda B \lambda x \lambda$ e.resource-controller $(e, x) \wedge B(e, x) \wedge$ generous $(e)$

b. $\lambda e$.resource-controller $(e$, rebecca $) \wedge$ donate-3oo-euros-to-the-mu$\operatorname{seum}(e, x) \wedge \operatorname{generous}(e)$

However, we observe that such an analysis would leave the properties of being generous and of being a donate-3oo-euros event completely unconnected: 
(5ob) may be true while $e$ 's property of being generous has nothing to do with $e$ 's property of being a donate-3oo-euros event, while intuitively, those are intimately related. This tight connection is well captured in (46)-(47).

In a nutshell, we propose to extend Piñón's (2016) analysis of evaluative behavior-related adjectives to pancake sentences as follows. The nominal expression under its pancake reinterpretation describes an event type $P$ involving an entity $x$ satisfying the nominal predicate in its literal meaning as theme. Take for instance sentence (51) in its pancake interpretation (see the example (6b) and the related comments in the introduction on the ambiguity of sentences such as (51)). The nominal expression estudante receives the literal meaning (52). We adopt Müller's (2002, 288) claim that the denotation of numberless count common nouns in Brazilian Portuguese contains both singular (atomic) and plural (non-atomic) entities (i.e., it neutralizes the singular/plural distinction). In the derived pancake interpretation, the same nominal expression receives the meaning (53), where $P$ stands for a one place predicate of events $e$ involving an (atomic or non-atomic) individual $x$ which is/are stu$\operatorname{dent}(\mathrm{s})$ as theme and an individual $y$ as agent. The inclusion of an agent argument is motivated by the fact that implicit event types expressed by the subject of pancake sentences always seem to be agentive, in French as in Brazilian Portuguese. We come back to the specific translation we attribute to (51) in Section $3 \cdot 3 \cdot$

(51) Estudante é interessante.

student.M.SG be.3SG.PRs interesting.M.SG

'(Relevant) agentive event types with students as theme (teaching, supervising them, talking with them ...) are generally interesting.'

(52) 【estudante literal $\rrbracket^{c, g, w, t, S p}=$ $\lambda x$.student $(x) \wedge(\operatorname{AT}(x) \vee \neg \operatorname{AT}(x))$

'The set of (atomic or non-atomic) individuals which are students.'

(53) $\llbracket$ estudante ${ }_{\text {pancake }} \rrbracket^{c, g, w, t, S p}=$ $\lambda y \lambda P \lambda x \lambda e . P(e) \wedge$ theme $(e, x) \wedge \operatorname{student}(x) \wedge(\operatorname{AT}(x) \vee \neg \operatorname{AT}(x)) \wedge$ $\operatorname{agent}(e, y)$

'The set of event types that have an (atomic or non-atomic) individual $x$ which is/are student(s) as theme and an individual $y$ as agent.'

We propose to capture this reinterpretation mechanism by a covert 'pancake' operator (that we symbolise by ' $\circledast$ '), see (54a). The operator in (54a) expresses a relation between a property $N$ of individuals, a property $P$ of events and indi- 
viduals $x$ and $y$ and yields the conditions that $x$ is $N, e$ is $P, x$ is the theme of $e$ and $y$ the agent of $e$. Applied to an individual-denoting nominal predicate $N$, it returns a relation between event types $P$, individuals $x$ and $y$ and events $e$, and yields the condition that $x$ satisfies $N, e$ satisfies $P, x$ is the theme of $e$ and $y$ is the agent of $e$, see $(54 \mathrm{~b})$.

(54) a. $\circledast=\lambda N \lambda y \lambda P \lambda x \lambda \lambda e . N(x) \wedge P(e) \wedge$ theme $(e, x) \wedge$ agent $(e, y)$

b. $N_{\circledast}=\lambda y \lambda P \lambda x \lambda e . N(x) \wedge P(e) \wedge$ theme $(e, x) \wedge \operatorname{agent}(e, y)$

c. Superviser les étudiants $\left(c^{\prime}\right)$ est supervise.INF the.PL student.M.PL (DEM) be.3SG.PRS intéressant. interesting.M.SG 'Supervising students (, that) is interesting.'

For French, we assume that the pancake operator (which, as we will see, has a slightly different meaning than (54a)) is encoded by the pronoun ce. Obviously, it is not active when the subject overtly denotes an event type, for then, no reinterpretation of the subject is needed to obtain the target interpretation. And note that in French, the pronoun $c e$ is not compulsory with such subjects, see (54c). The pancake operator is semantically active only when a type mismatch arises between an individual-denoting nominal expression and a predicate of event types. It is the lack of agreement in gender and number between the subject and the predicate which signals that the predicate is not meant to be composed with the subject in its literal individual-denoting meaning, but is rather used as a predicate applying to a (covert) first order event predicate. Arguably, the presence vs. lack of agreement can be modelled along the lines of systems of dual agreement (syntactic vs. semantic); see for instance Landau (2016), Smith (2015) and Wechsler and Zlatić (2000) for some alternatives.

\subsection{Episodic Pancake Semantics}

French pancake sentences can have an episodic use, as for instance in (55), differently from what happens in Brazilian Portuguese, where they are necessarily generic (see Section 3.3). Note that in the episodic use, the subject does not receive a generic interpretation. ${ }^{10}$ In (55), the possessive or the demonstrative as well as the past tense and the temporal adverbial promote the episodic read-

10 See Roy and Shlonsky (2019) on the alternative view that subjects of non-agreeing copular sentences must receive a generic interpretation. 
ing. ${ }^{11}$ We assume that the speaker asserting a pancake sentence in its episodic use always has in mind a particular event type $P_{c}$ which justifies the assertion (see Heller 1999 and Greenberg 2008 on the related proposal that the original denotation of the subject of Hebrew pancake sentences is 'widened' to a contextually retrievable property involving the original denotation). The specific event type $P_{c}$ behind the assertion obviously depends on the speaker and the context of use (think of (55) uttered by a teacher, a taxi driver or a drug dealer). ${ }^{12}$

(55) French

(Hier, les/mes/ces étudiants, c'était

yesterday the/my/these.M.PL student.M.PL DEM=be.3SG.IMPF

intéressant.

interesting.M.SG

'(Yesterday,) supervising the/my/these students (or teaching them, or talking with them, or driving them home, or selling them drugs, or ...) was interesting.'

Since the overt nominal expression in (55) is individual-denoting, in order to derive the pancake meaning, we need a pancake operator that has a slightly different meaning than (54a), since this operator must take an individual as its first argument. The meaning of the pancake operator for the episodic use, that we dub ' $\odot$ ', is provided in (56a): it takes an individual $x$ and an individual $y$, an event property $P$ and an event $e$ as its arguments and yields the conditions that $e$ is $P, x$ is the theme of $e$ and $y$ is the agent of $e .^{13}$ Applied to the definite expression les étudiants, (56b) obtains. Once a specific event type $P_{c}$ (e.g., the property of supervising) saturates the lambda term $\lambda P$, we obtain the meaning $(56 \mathrm{c})$.

11 When the episodic use is selected, the dislocated noun cannot host the weak indefinites des/un 'some/a', while such indefinites are as a rule acceptable in generic pancake sentences, as indicated in the examples in Section 1 (but see footnote 20). This is unsurprising, for in French, weak indefinites are as a rule unacceptable in episodic contexts when dislocated.

12 The role of the speaker and what they have in mind is taken up by Ihsane (this volume), in connection with specificity and telicity.

Note that "partitive articles" are often unacceptable in subject position with evaluative predicates such as intéressant 'interesting'. For instance, des étudiants étaient intéressants 'students were interesting' is marginal in French, as is its English counterpart with a bare noun subject under a stage-level reading of interesting (see Martin 2009, Dobrovie-Sorin and Beyssade 2012 and references therein).

13 One could avoid a second entry for the pancake operator by assuming that les étudiants under its literal meaning is a predicate (denoting the set of entities that are identical to the students). 
(56) a. $\odot=\lambda x \lambda P \lambda y \lambda e . P(e) \wedge$ theme $(e, x) \wedge \operatorname{agent}(e, y)$

b. $\llbracket$ les étudiants $\odot \rrbracket^{c, g, w, t, S p}=$ $[\lambda x \lambda P \lambda y \lambda e . P(e) \wedge$ theme $(e, x) \wedge$ agent $(e, y)]($ the-students $)=($ by application)

$\lambda P \lambda y \lambda e . P(e) \wedge$ theme $(e$, the-students $) \wedge$ agent $(e, y)$

'The set of event types that have the students as theme and an individual $y$ as agent.'

c. 【les étudiants $\rrbracket_{\odot} \rrbracket^{c, g, w, t, S p}\left(P_{c}\right)=$ (by application) $\lambda y \lambda e . P_{c}(e) \wedge$ theme $(e$, the-students $) \wedge$ agent $(e, y)$

'The set of events of a contextually retrievable event type $P_{c}$ that have the students as theme and an individual $y$ as agent.'

We want the postcopular adjective to have the same meaning in pancake sentences with a DP/NP subject and in sentences that have an infinitival subject, as for instance (57).

(57) French

Superviser les étudiants était intéressant. supervise.INF the.PL student.M.PL be.3SG.IMPF interesting.M.SG 'Supervising the students was interesting.'

We propose that in pancake sentences, interesting refers to an experience event like any experiencer predicate, just like in the other uses (Bylinina 2017). However, while interesting denotes a first-order property when its external argument refers to an individual or an event (see The students/the classes were interesting), it denotes a second-order property predicated of an event type when its subject denotes a set of events, as in pancake sentences, or in (57) (or in Piñón's example (45) built with the adjective generous). The idea that the subject of pancake sentences is interpreted as denoting an event type will be motivated below (see the discussion about (66) and (75)-(78)). We label this use the "2d-ord" use, see (58). When the experiencer argument is implicit as in (55), we assume with Epstein (1984) and subsequent authors that the position is occupied by a silent pronoun pro (for simplicity, we omit in (58) the degree semantics necessary to account for the fact that interesting is also gradable in its second order use, but ultimately, it should be added to (58); also, following Bylinina 2017, we formulate the 'judge=experiencer' requirement as a presupposition in (58a)). 
(58) 【intéressant ${ }_{2 \mathrm{~d} \text {-ord }} \mathbf{p r o}_{5} \rrbracket^{c, g, w, t, S p}=$

a. defined iff $S p=g(5)$ (judge $=$ experiencer)

b. $\lambda P \lambda e . P(e) \wedge \operatorname{experiencer}(e, g(5)) \wedge$ interesting $\left(\lambda e^{\prime} . P\left(e^{\prime}\right)\right)$ for $S p$ at $t$ in $w$

Like any other experiencer predicate, interesting $_{2 \mathrm{~d} \text {-ord }}$ projects an experiencer argument, and like any other evaluative predicate, its content is evaluated with respect to a judge parameter $j$ (set to the speaker $S p$ in absence of a judgeshifting expression such as $f i n d)$. The predicate in (58b) applies to a one-place event predicate $P$, an event $e$, and yields the condition that pro is the experiencer of $e$, and that the event type $P$ is an interesting type of events for the speaker at $t$ in $w$.

Let us now return to the French sentence (55). A crucial property of (55) is that it triggers an actuality entailment (Hacquard 2006): it entails that an event satisfying the implicit event type took place (e.g., there was a supervising of the students), which is something we have to account for. Furthermore, Bhatt and Pancheva (1997) have shown that when predicates of personal taste are built with an infinitival subject, the experiencer argument must control the PRo subject of the infinitive (see their examples $(20)-(22)$ and (50)). The same is true in Brazilian Portuguese or French. For instance, in (59a), the experiencer projected by funny or stressful is necessarily also the subject of the infinitive. Similarly in (59b), the experiencer of the fun is necessarily identical with the agent of danser 'dance..14 Landau (2013) also showed that adjectives such as interesting or difficult force obligatory control on their subject; see for instance his example (59c), which forces the experiencer John to be the problem solver.

(59) a. $\boldsymbol{P R O}_{i}$ lidar com/ter criança é divertido/estressante (para deal.INF with/have.INF child.F.SG is funny/stressful for João $o_{i}$.

John

'Having/dealing with children is generally funny/stressful [for/to John].'

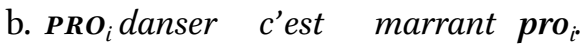

dance.INF DEM.is fun.M.SG

'To dance is fun.'

14 Bhatt and Pancheva (1997) argue that in English, infinitival subjects and gerunds differ in 
c. Mary ${ }_{\mathrm{j}}$ thought that $\mathrm{PRO}_{\mathrm{i} / *_{\mathrm{j}} /{ }^{*} \text { arb }}$ solving the problem by himself/*herself/*oneself would be easy/difficult for Peter ${ }_{\mathrm{i}}$ (Landau 2013, 41)

In pancake sentences, whose subject is individual-denoting on its literal meaning, a similar relation arises: the experiencer/judge projected by the adjective must be identical with the agent participant of the event type denoted by the pancake subject. For instance, in (55), the judge who finds the $P$-event type interesting and experiences such a $P$-event must also be the implicit agent introduced by the subject (and remember from Section 2.2. that under Bylinina's understanding, the experiencer of an event $e$ may be the agent of $e$ ). We capture this in the analysis by assuming that the agent argument $y$ of the event type $P_{c}$ is realized syntactically as the covert pronoun PRO and semantically as a free variable, here indexed by 8 , see (6oa-b).

(6o) a. 【les étudiants $\rrbracket_{\odot} \rrbracket^{c, g, w, t, S p}=$ $\lambda y \lambda e . P_{c}(e) \wedge$ theme $(e$, the-students $) \wedge \operatorname{agent}(e, y)$

b. $\llbracket \mathbf{P R O}_{8}$ les étudiants $\odot \rrbracket^{c, g, w, t, S p}=$ $\lambda e . P_{c}(e) \wedge$ theme $(e$, the-students $) \wedge$ agent $(e, g(8))$

Furthermore, we want the experiencer argument of the predicate of personal taste to control this covert pronoun PRo. Thus, when pro occupies the experiencer argument of interesting ${ }_{2 \mathrm{~d}-\text { ord }}$ it must also determine the referent of the agent argument PRO projected by les étudiants ${ }_{\odot}$. To keep it simple-and as a consequence, to keep the binding mechanism implicit—we analyze (55) as in (61):

(61) $\llbracket \mathbf{P R O}_{8}$ les étudiants ${ }_{\odot}$ être intéressant ${ }_{2 \mathrm{~d} \text {-ord }} \mathbf{p r o}_{5} \rrbracket^{c, g, w, t, S p}=$ $\left[\lambda P \lambda e . P(e) \wedge\right.$ experiencer $(e, g(5)) \wedge$ interesting $\left.\left(\lambda e^{\prime} . P\left(e^{\prime}\right)\right)\right]$ $\left(\lambda e . P_{c}(e) \wedge\right.$ theme $(e$, the-students $) \wedge$ agent $\left.(e, g(8))\right)=($ by application and control of the agent by the experiencer)

a. $\lambda e . P c(e) \wedge$ theme $(e$, the-students $) \wedge$ agent $(e, g(8)) \wedge$ experien$\operatorname{cer}(e, g(8)) \wedge$ interesting $\left(\lambda e^{\prime} . P_{c}\left(e^{\prime}\right) \wedge\right.$ theme $\left(e^{\prime}\right.$, the-students $) \wedge$ $\left.\operatorname{agent}\left(e^{\prime}, g(8)\right)\right)$ for $S p$ at $t$ in $w$

b. defined iff $S p=g(8)$ (judge=experiencer)

this respect: while to dance is fun patterns with French $(59 \mathrm{~b})$, requiring that the experiencer is necessarily the dancer, dancing is fun leaves open the possibility that the implicit experiencer of fun is distinct from the agent of dancing. 
Once the imperfective applies, the event variable gets existentially quantified:

(62) $\llbracket \operatorname{IMPF}\left(\mathbf{P R O}_{8}\right.$ les étudiants $\odot$ être intéressant $\left.{ }_{2 \mathrm{~d}-\text { ord }} \mathbf{p r o}_{5}\right) \rrbracket^{c, g, w, t, S p}=$ a. $\exists e . t_{T} \subseteq \tau(e) \wedge P_{c}(e) \wedge$ theme $(e$, the-students $) \wedge \operatorname{agent}(e, g(8))$ $\wedge$ experiencer $(e, g(8)) \wedge$ interesting $\left(\lambda e^{\prime} . P_{c}\left(e^{\prime}\right) \wedge\right.$ theme $\left(e^{\prime}\right.$, thestudents) $\wedge$ agent $\left.\left(e^{\prime}, g(8)\right)\right)$ for $S p$ at $t$ in $w$

b. defined iff $S p=g(8)$ (judge $=$ experiencer)

According to (62), assuming that sentence (55) is uttered by John, (55) states that there was an event $e$ of a (contextually retrievable) type $P_{c}$ whose temporal trace includes the topic time, such that $e$ has the students as theme and John as experiencer and agent, and such that the event type $P_{c}$ involving the students as theme and John as agent is an interesting event type for John. We thus express that (55) triggers an actuality entailment. ${ }^{15}$

We can now analyze (57) along the same lines. We assume that the agent argument of the event type denoted by the infinitival subject is occupied by PRO, who must be controlled by pro, see (63)-(64):

(63) a. 【superviser les étudiants $\rrbracket^{c, g, w, t, S p}=$ $\lambda y \lambda e$.supervise $(e) \wedge$ theme $(e$, the-students $) \wedge \operatorname{agent}(e, y)$

b. $\llbracket \mathbf{P R O}_{8}$ superviser les étudiants $\rrbracket^{c, g, w, t, S p}=$ $\lambda e$.supervise $(e) \wedge$ theme $(e$, the-students $) \wedge \operatorname{agent}(e, g(8))$

(64) $\llbracket \mathbf{P R O}_{8}$ superviser les étudiants être intéressant ${ }_{2 \mathrm{~d}-\text { ord }} \mathbf{p r o}_{5} \rrbracket^{c, g, w, t, s p}=$ $\left[\lambda P \lambda e . P(e) \wedge\right.$ experiencer $(e, g(5)) \wedge$ interesting $\left.\left(\lambda e^{\prime} . P\left(e^{\prime}\right)\right)\right]$ $(\lambda e$.supervise $(e) \wedge$ theme $(e$, the-students $) \wedge$ agent $(e, g(8))=$ (by application and control of the agent by the experiencer)

a. $\lambda e$.supervise $(e) \wedge$ theme $(e$, the-students $) \wedge \operatorname{agent}(e, g(8)) \wedge$ experiencer $(e, g(8)) \wedge \operatorname{interesting}\left(\lambda e^{\prime} \cdot \operatorname{supervise}\left(e^{\prime}\right) \wedge \operatorname{theme}\left(e^{\prime}\right.\right.$, the-students) $\wedge$ agent $\left.\left(e^{\prime}, g(8)\right)\right)$ for $S p$ at $t$ in $w$

b. defined iff $S p=g(8)$ (judge=experiencer)

15 In fact, the occurrence of the experience event satisfying the contextually salient event type $P_{c}$ seems presupposed rather than entailed by evaluative statements with predicates of personal taste (as Bylinina 2017, 323 observes, the cake is not tasty still suggests that the speaker has tried the cake, and the negation of (55) triggers the inference that a supervising (or teaching, etc.) of students took place). Since our account is coached in a non-dynamic semantics, we do not make justice to this fact. 
Let us now add the imperfective again:

(65) $\operatorname{IMPF}\left(\mathbf{P R O}_{8}\right.$ superviser les étudiants être intéressant $\left.{ }_{2 \mathrm{~d}-\text { ord }} \mathbf{p r o}_{5}\right) \rrbracket^{c, g, w, t, S p}$ $=$

a. $\exists e . t_{T} \subseteq t(e) \wedge$ supervise $(e) \wedge$ theme $(e$, the-students $) \wedge$ agent $(e$, $g(8)) \wedge$ experiencer $(e, g(8)) \wedge$ interesting $\left(\lambda e^{\prime}\right.$.supervise $\left(e^{\prime}\right) \wedge$ theme $\left(e^{\prime}\right.$, the-students $\left.) \wedge \operatorname{agent}\left(e^{\prime}, g(8)\right)\right)$ for $S p$ at $t$ in $w$

b. defined iff $S p=g(8)$ (judge $=$ experiencer)

According to $(65),(57)$ has the same meaning as $(55)$ in a context where $P_{\mathrm{c}}$ is the property of supervising (students), which is the desired result. ${ }^{16}$

One of the motivations for treating the predicate of personal taste in pancake sentences as a second-order predicate as in (61) or (64) is that by doing so, we explicitly require that the contextually retrievable event type $P_{c}$ is an interesting thing to do, which is intuitively what a pancake sentence such as (55) asserts. In contrast, when interesting is used as a first-order predicate of events - as we assume with Bylinina (2017) to be the case with an eventdenoting nominal expression (e.g., the class, the ride, recall (34c)) - it is simply stated that $e$ is an interesting event. Thus first-order and second-order evaluative statements built with predicates of personal taste do not entail each other. This is illustrated in examples $(66 \mathrm{a}-\mathrm{b})$, where interesting $_{2 \text {-ord }}$ is predicated of an event type $P$, and boring $_{\text {1st-ord }}$ predicated of an event $e$ of type $P$ (or vice-versa).

(66) a. The travel/the drive was interesting 1st-ord $_{\text {(but to travel/to drive was }}$ totally boring $\left.{ }_{2 \mathrm{~d}-\mathrm{ord}}\right)$.

b. To drive the students was interesting ${ }_{2 d-o r d}$ (but the drive itself was totally boring $\left.{ }_{\text {sts-ord }}\right)$.

These examples are not contradictory precisely because evaluative statements of first and second order operate at different levels. Driving the students

16 As a side note, we observe that the evaluation time $t$ at which is made the evaluation that supervising students is an interesting event type does not depend from the event time of the experience (supervising) event. That is, the evaluation time $t$ is not determined by the (im-)perfective aspect on the copula. For the speaker may realize only a posteriori that the event he experienced was an interesting type of event, without understanding it while $\mathrm{s} /$ he was experiencing it. More concretely, there is no contradiction in the following statement:

(i) Superviser les étudiants aété/était intéressant, même si je supervise.INF the.PL student.M.PL be.3SG.PFV/IMPF interesting.M.SG even if I ne m'en suis pas renducompte au moment même. NEG REFL.1SG=PART be.1SG. NEG realized at-the moment same 'Supervising the students was interesting, although I didn't realize it at that moment.' 
may have been a boring event type for John while the drive itself was exciting, for the students were such great conversation partners, for instance. Or on the contrary, the drive itself may have been very boring because the students were not willing to talk, while to drive them home was very exciting.

\subsection{Generic Pancake Semantics}

In Brazilian Portuguese, pancake sentences are necessarily generic. (The copula estar used in episodic readings of copular sentences is not licensed to begin with.) So for instance, $(67)$ cannot mean that a (contextually restricted) event type involving children as theme was funny in a particular occasion in the past. It can only mean that in the past, (contextually retrievable) event types involving children as theme were generally funny. Also, perfective markers, which enforce the episodic reading in French, are forbidden in Brazilian Portuguese in a neutral context, see (68).

(67) Brazilian Portuguese

Criança era engraçado.

child.F.SG be.3SG.IMPF funny.M.sG

'Dealing with/taking care of/playing with the children was (in general/ always) funny'

(68) \#Criança foi difícil.

child.F.SG be.3SG.PFV difficult.M.SG

Intended: 'Dealing with/taking care of/playing with the children was difficult [on a particular occasion].'

Another related difference between Brazilian Portuguese and French is that French pancake sentences may be generic while their subjects refer to specific individuals (see also Ihsane's contribution on specificity in this volume). For instance, sentences (69)-(70) may be used to express generalities about an event type involving specific individuals. In contrast, in Brazilian Portuguese, determiners needed to enforce the specific reading of the nominal expression are forbidden in pancake sentences, see (71), as well as modifiers inducing the specific reading of the bare $\mathrm{NP}$, see (72).

(69) French

Nos enfants, c'est difficile.

our child.M.PL DEM=be.SG.PRS difficult.M.SG

'Dealing with our [particular] children is (in general/always) complicated.' 
(70) Les étudiants qui viennent de débarquer dans la the.PL student.M.PL who come.3PL.PRS to land.INF in the classe, c'est très sympa.

class.F.SG DEM=be.3SG.PRS very nice.M.SG

'Teaching/dealing with ... the students that have just arrived in the class is (in general/always) very nice.'

(71) Brazilian Portuguese

*Nossas crianças é difícil.

our.F.PL child.F.SG be.3SG.PRS difficult.M.SG

Intended: 'Dealing with our children is (in general) difficult.'

(72) * Criança que acabou de chegar na sala é child.F.SG that finished of arrive.INF in.the class be.3SG.PRS dificil.

difficult.M.sG

Intended: 'Teaching, dealing with ... the students that have just arrived in the class is (in general) difficult.'

We propose that the generic interpretation of pancake sentences arises from quantification by gen on event types and individuals involved in these event types. ${ }^{17} \mathrm{An}$ argument for this is that intuitively, a sentence such as (51) repeated below seems in its pancake reading to describe a generalization on (contextually restricted) event types involving students, rather than making a generalization about a specific event type recovered in the context.

(51) Brazilian Portuguese

Estudante é interessante.

student.M.SG be.3SG.PRS interesting.M.SG

'(Relevant) agentive event types with students as theme are generally interesting.'

We thus apply the $\circledast$-operator in (54a) to the nominal predicate estudante and we obtain (73a). In (73b), PRO occupies the agent argument of the event type in $(73 a)$.

17 This is in line with previous accounts of bare singular nouns in Brazilian Portuguese as Heimian indefinites (Müller 2002 a.o.). As in other constructions in Brazilian Portuguese, the bare noun in subject position is bound by gen. 
(73) a. $\llbracket$ estudante $\rrbracket_{\circledast} \rrbracket^{c, g, w, t, S p}=$ $\lambda y \lambda P \lambda x \lambda e . \operatorname{student}(x) \wedge P(e) \wedge$ theme $(e, x) \wedge(\operatorname{AT}(x) \vee \neg \mathrm{AT}(x)) \wedge$ $\operatorname{agent}(e, y)$

b. $\llbracket \mathbf{P R O}_{8}$ estudante $_{\circledast} \rrbracket^{c, g, w, t, S p}=$ $\lambda P \lambda x \lambda$ e.student $(x) \wedge P(e) \wedge$ theme $(e, x) \wedge(\mathrm{AT}(x) \vee \neg \mathrm{AT}(x)) \wedge$ $\operatorname{agent}(e, g(8))$

This time, we do not apply (73) to a contextually retrieved event type $P_{\mathrm{c}}$ (as we did for the episodic use in French). Instead, we now quantify over the variable $P$ with gen. The subject estudante $\circledast$ serves as the restrictor of gen, and the result of the application of interessante $_{2 \text {-ord }}$ to estudante $\circledast$ as its nuclear scope, see (74). We adopt the default null hypothesis that Brazilian Portuguese interessante $_{2 \mathrm{~d} \text {-ord }}$ has the same semantics as French intéressant ${ }_{2 \mathrm{~d} \text {-ord }}$ in (58) (repeated partly below). Furthermore, the 'judge=experiencer' requirements is again in force, and the agent is controlled by the experiencer as before.

(58) 【intéressant ${ }_{2 \mathrm{~d} \text {-ord }}$ pro $_{5} \rrbracket^{c, g, w, t, S p}=$

a. defined iff $S p=g(5)$ (judge $=$ experiencer)

b. $\lambda P \lambda e . P(e) \wedge \operatorname{experiencer}(e, g(5)) \wedge$ interesting $\left(\lambda e^{\prime} . P\left(e^{\prime}\right)\right)$ for $S p$ at $t$ in $w$

(74) $\operatorname{gen}\left[\mathbf{P R O}_{8}\right.$ estudante $\left._{\circledast}\right]\left[\left[\right.\right.$ interessante $_{2 \text {-ord }}$ pro $\left._{5}\right]\left(\mathbf{P R O}_{8}\right.$ estudante $\left.\left._{\circledast}\right)\right]=($ by application and control of the agent by the experiencer)

a. gen $P, x, e[\operatorname{student}(x) \wedge P(e) \wedge$ theme $(e, x) \wedge(\operatorname{AT}(x) \vee \neg \mathrm{AT}(x)) \wedge$ $\operatorname{agent}(e, g(8))][P(e) \wedge \operatorname{theme}(e, x) \wedge(\operatorname{AT}(x) \vee \neg \operatorname{AT}(x)) \wedge$ $\operatorname{agent}(e, g(8)) \wedge \operatorname{experiencer}(e, g(8)) \wedge \operatorname{interesting}\left(\lambda e^{\prime} . P\left(e^{\prime}\right) \wedge\right.$ $\operatorname{student}(x) \wedge$ theme $\left.\left.\left(e^{\prime}, x\right) \wedge(\mathrm{AT}(x) \vee \neg \mathrm{AT}(x)) \wedge \operatorname{agent}\left(e^{\prime}, g(8)\right)\right)\right]$ for $S p$ at $t$ in $w$ in the context $c$.

b. defined iff $S p=g(8)$ (judge=experiencer)

Unpacking (74), we obtain (74a), which is defined iff the presupposition in (74b) is met. According to (74a), assuming that John is the speaker of (51), sentence (51) states that for all event types $P$, individuals $x$ and events $e$, if $e$ is $P, x$ is a student and the theme of $e$ and John the agent of $e$, then John is the experiencer of $e$ and $P$ is an interesting event type for John at $t$ in $w$ in the context $c$.

The values of $P$ are given by the domain of quantification of gen, which is limited by the context $c$. Nevertheless, (74a) is arguably too weak, for (51) might be true while many agentive event types retrievable from the context $c$ that have students as theme and performed by John are not at all interesting for John (such as watching students entering the class, for instance). The set of 
event types which are said to be interesting event types should probably be restricted to stereotypical event types through which the agent interacts with the theme (and this set of event types will drastically vary from experiencer to experiencer: think again of (51) uttered by a teacher, a taxi driver or a drug dealer). We leave the technical implementation of a solution along these lines for further research. As C. Piñón (p.c.) observes, another issue raised by our account is that it is more complex than necessary, mainly because we assume that interessante $e_{2 \text {-ord }}$ functionally applies to estudante $_{\circledast}$. This is especially clear in (74), where interessante ${ }_{2 \text {-ord }}$ applies to estudante ${ }_{\circledast}$ in the consequent of the conditional. A revised version of estudante $_{\circledast}$ and interessante $_{2 \text {-ord }}$ that leads to a simpler account of generic (and episodic) sentences is also left for further research.

\subsection{Predicates of Personal Taste Used as First-Order Predicates}

Predicates of personal taste can also be used as first-order predicates over events or individuals. With Bylinina (2017), we assume that in this use too, experiencer adjectives refer to an experience event. One of the facts we need to explain is the absence of entailment between a sentence where interesting or funny is used as a second-order predicate of event types, and a sentence where the same adjective is used as a first-order predicate of events or individuals. For instance, as Greenberg (2008) observes for Hebrew, there is no relation of entailment between (75) and (76), see the absence of contradiction in (77)(78).

(75) French

Les étudiants c'était intéressant.

the.PL student.M.PL DEM=be.3SG.IMPF interesting.M.SG

'Supervising (or teaching, or selling drugs to) ... the students was interesting.'

(76) Les étudiants étaient intéressants.

the.PL student.M.PL be.3PL.IMPF interesting.M.PL

'The students were interesting.'

(77) Les étudiants c'était intéressant, mais les the.PL student.M.PL DEM=be.3SG.IMPF interesting.M.SG but the.PL étudiants ne l'étaient pas. student.M.PL NEG it=be.3PL.IMPF NEG.

'Doing something with the students was interesting, but the students were not.' 
(78) Les étudiants étaient marrants. Mais les

the.PL student.M.PL DEM=be.3PL.IMPF funny.M.SG but the.PL

étudiants, c'était pas marrant.

student.M.PL DEM=be.3SG.IMPF NEG funny.M.SG

'The students were funny. But the students, that was not funny.'

We analyze predicates of personal taste used as first order predicates along the lines of Bylinina (2017), see (79).

(79) 【intéressant ${ }_{1 \mathrm{st}-\mathrm{ord}}$ pro $_{5} \rrbracket^{c, g, w, t, S p}=$

a. $\lambda x \lambda e \cdot \operatorname{stimulus}(e, x) \wedge \operatorname{experiencer}(e, g(5)) \wedge \operatorname{interesting}(e)$ for $S p$ at $t$ in $w$

b. $S p=g(5)$ (judge $=$ experiencer $)$

Applying this predicate to the definite expression les étudiants under its literal meaning, and assuming as before that pro saturates the experiencer argument, we obtain the meaning in (8o), i.e, a set of events $e$ such that the students are the stimulus of $e$, pro the experiencer of $e$ and $e$ is an interesting event for the speaker at $t$ in $w$.

(80) 【les étudiants être intéressant ${ }_{1 \text { st-ord }}$ pro $_{5} \rrbracket^{c, g, w, t, S p}=$

a. $[\lambda x \lambda e . \operatorname{stimulus}(e, x) \wedge \operatorname{experiencer}(e, g(5)) \wedge$ interesting $(e)]$ for $S p$ at $t$ in $w$

(the-students) $=($ by application $)$

$\lambda e . s t i m u l u s(e$, the-students $) \wedge \operatorname{experiencer}(e, g(5)) \wedge$ interest$\operatorname{ing}(e)$ for $S p$ at $t$ in $w$

b. $S p=\mathrm{g}(5)$ (judge $=$ experiencer)

The absence of entailment from $(76)$ to $(75)$ is due to the fact that an event that makes (8o) true does not necessarily make (61) (partly repeated below) true. To elaborate on a previous example, imagine for instance that John, a taxi driver, found the conversation with the students he drove home interesting. In that case, the conversation may be the interesting experience event having the students as stimulus, thus (76) (and (80)) are satisfied. Now, imagine that the contextually salient event type $P_{c}$ is driving the students home. The situation just assumed making $(76) /(80)$ true doesn't ensure that $P_{c}$ is an interesting event type, for John may find the conversation with the students interesting and nevertheless find driving the students home a very boring thing to do. 
(61) $\llbracket \mathbf{P R O}_{8}$ les étudiants $_{\odot}$ être intéressant ${ }_{2 \mathrm{~d}-\text { ord }}$ pro $_{5} \rrbracket^{c, g, w, t, S p}=$

a. $\lambda e . P_{c}(e) \wedge$ theme $(e$, the-students $) \wedge$ agent $(e, g(8)) \wedge$ experien$\operatorname{cer}(e, g(8)) \wedge$ interesting $\left(\lambda e^{\prime} . P_{c}\left(e^{\prime}\right) \wedge\right.$ theme $\left(e^{\prime}\right.$, the-students $) \wedge$ $\left.\operatorname{agent}\left(e^{\prime}, g(8)\right)\right)$ for $S p$ at $t$ in $w$

b. defined iff $S p=g(8)$ (judge $=$ experiencer)

The fact that the reverse entailment from $(75)$ to $(76)$ does not hold either can be explained along the same line.

Accounting for the Variations between Brazilian Portuguese and French

We observed in the previous sections that while in Brazilian Portuguese nonagreeing copular sentences under study must be pancake sentences, this is not the case in French. Sections 4.1 and 4.2 below aim to account for this difference. We first address the question of why the pancake interpretation is optional for French non-agreeing copular sentences in Section 4.1.

\subsection{Why Is the Pancake Interpretation Optional in French?}

As mentioned in the introduction, French non-agreeing copular sentences indisputably have a dislocated structure (as indicated by the comma in our examples), and have two subject positions, one filled by the left dislocated DP, which is the higher one, and the second filled by the neuter pronoun $c e$, the lower one (cf. Roy and Shlonsky 2019). This is schematically indicated in (81).

(81) les légumes SUBJ2 [ce subj1 [TP est [PREDP [DP les légumes] [PRED [AP vert]]]] (Roy and Shlonsky 2019)

We observe one exception to this generalization: when the subject is a numeral, French tolerates non-agreement with the predicate even in absence of $c e$ and left-dislocation, see (82). Note that in these sentences, the subject receives the event type reading characteristic of pancake sentences. We briefly come back to this exception in Section 5 .

(82) French
a. Dix invités
est
vraiment trop difficile.
ten guest.M.PL be.3SG.PRS really too complicated.M.SG
'(Dealing with) ten guests is really too complicated.' 

b. ${ }^{*}$ Les invités est vraiment trop difficile.
the.PL guest.M.PL be.3SG.PRS really too complicated.M.SG
Intended: '(Dealing with) the guests is really too complicated.'

We assume that in presence of $c e$, the adjective agrees with this neuter pronoun, and therefore receives default agreement, which is singular/masculine in French. At first sight, the antecedent of $c e$ seems to be the dislocated DP. When the dislocated DP is plural and/or feminine, a mismatch arises between the phi-features of the nominal expression and those of $c e$ (and of the adjective agreeing with $c e$ ). Why is it so?

We argue that as in all other languages with pancake sentences, the mismatch is the expression of the fact that $c e$ in fact agrees with a non-overt structure, which is its true antecedent, for which the nominal expression stands for. However, the meaning of this non-overt structure may vary a lot. That ce may induce a wide range of reinterpretations of the nominal expression serving as its antecedent is a well-known fact in French linguistics (Furukawa 1988, Cadiot 1988, Carlier 1996, Reed 1997, a.o). We here only briefly illustrate the most relevant meaning shifts typically triggered by $c e$.

The first reinterpretation of the dislocated nominal expression triggered by $c e$ is the one obtained in pancake sentences. For this case, the semantics we attributed to the covert structure involved in pancake sentences obtains, see Section 3. In a second case, the covert antecedent of $c e$ denotes a situation or state-of-affairs involving the individual denoted by the nominal expression in its literal meaning, and the adjective attributes a property to this situation, rather than to the theme of this situation. For instance, (83a) asserts that the situation of dead-leaves-in-the-garden is beautiful; the dead leaves themselves involved in this situation need not be. In contrast, $(83 \mathrm{~b})$ attributes beauty to the dead leaves themselves. Similarly, (84a) attributes redness to the birds-in-thesunset situation; the same birds do not have to be red themselves. In contrast, $(84 \mathrm{~b})$ entail that the birds themselves are red (at least if the locative modifier is in preverbal position). ${ }^{18}$

18 If the modifier is in post-verbal position (Les oiseaux sont rouges dans le coucher du soleil 'The birds are red in the sunset'), it gets a restrictive reading. Restrictive modifiers often trigger a causal relation between their descriptive content and the main predication (thus, the latter sentence conveys that the birds are red because they are in the sunset), see Martin (2014) and references therein. Because of this causal relation, the sentence with a post-verbal modifier does not entail anymore that the birds are red regardless of the circumstances, although redness is attributed to birds themselves. 
(83) French

a. Les feuilles mortes dans le jardin, c'est the.PL leaf.F.PL dead.F.PL in the.M.SG garden DEM=be.3SG.PRS beau.

beautiful.M.sG

'(The) dead leaves in the garden, that's beautiful.'

(situation)

b. Les feuilles mortes dans le jardin sont

the.PL leaf.F.PL dead.F.PL in the.M.SG garden be.3SG.PRS belles.

beautiful.F.PL

'The dead leaves in the garden are beautiful.'

(individual)

(84) a. Les oiseaux dans le coucherdusoleil, c'est

the.PL bird.M.PL in the sunset DEM=be.3SG.PRS

rouge.

red.M.s G

'The birds in the sunset, that's red.'

(situation)

b. Les oiseaux dans le coucherdusoleil sont rouges. the.PL bird.M.PL in the sunset be.3PL.PRS red.M.PL 'The birds in the sunset are red.'

(individual)

Under a third type of meaning shift induced by $c e$, the covert antecedent has a generic interpretation, while the DP under its literal reading can only have a specific interpretation with the post-copular adjective used. The fact that with some adjectives, $c e$ is necessary to get a generic interpretation of indefinites in subject position has been observed by Attal (1976) among others, see (85)-(86).

(85) French

Des enfants, c'est bruyant.

(generic only)

PA.PL child.M.PL DEM=be.3SG.PRS noisy.M.SG

'Kids are usually noisy.' Nот: 'Kids are (right now) noisy.'

(86) Des enfants sont bruyants.

(specific only)

PA.PL child.M.PL be.3PL.PRS noisy.M.PL

'Kids are (right now) noisy.' Nот: 'Kids are usually noisy.'

We observe through the contrast in $(87 \mathrm{a}-\mathrm{b})$ that at least with predicates of personal taste of the tasty-type, $c e$ is even required for the generic interpretation of definites in subject position. 
(87) French

a. Les crêpes, c'est

the.PL pancake.F.PL DEM=be.3sG.PRS

délicieux/savoureux.

(generic/specific)

tasty.M.SG

'(The) pancakes, that is (generally/right now) tasty.'

b. Les crêpes sont

the.PL pancake.F.PL be.3PL.PRS

délicieuses/savoureuses.

(specific only)

tasty.F.PL

'The pancakes are (right now) tasty'. Nот: 'Pancakes are usually tasty.'

In summary, ce may not only induce the event type reinterpretation of the individual-denoting dislocated DP, but also a situation/state-of-affairs or kindreinterpretation (see Furukawa 1988; Cadiot 1988; Carlier 1996; Reed 1997 for other meaning shifts of the dislocated DP triggered by $c e$, less relevant for the discussion; see also Gerards and Stark this volume, who develops a kindoriented mode of talk for the definite noun phrases found in the constituents traditionally analyzed as headed by a "partitive article" in Old Spanish). This is the reason why non-agreeing copular sentences do not have to be pancake sentences in French.

Before turning to Brazilian Portuguese, we wish to underline that it is $c e$ itself which brings in this range of potential reinterpretations for the dislocated DP, rather than ce combined with the copula. Evidence for the crucial role of $c e$ in these reinterpretation processes (including the one yielding a pancake reading of the dislocated subject) is that in French, they are also induced in non-copular sentences built with an experiencer predicate (but not in Brazilian Portuguese). For instance, (88a) does not mean that assistant professors make me laugh; what rather makes me laugh is what one is doing with them (e.g., paying them so little); similarly ( $88 \mathrm{~b}$ ) may be true although my children never get on my nerves; what (88b) asserts is that, e.g., caring for my children is too much for me. The same point could be made for the three other meaning shifts triggered by $c e$ briefly illustrated above. ${ }^{19}$

19 The counterparts of (88) in Brazilian Portuguese, when acceptable despite the lack of agreement, do not have a pancake interpretation: 
(88) French

a. Les ATER, ça me fait rire jaune.

the.PL ATER DEM me.ACC make.3sG.PRS laugh yellow '(Hiring) assistant professors, that doesn't make me laugh.'

b. Mes enfants parfois, ça m'emmerde.

my.M.PL child.M.PL sometimes DEM get.3SG.PRS on my nerves

'(Dealing with) my children, sometimes, that's too much for me.'

\subsection{Why Is the Pancake Interpretation Compulsory in Brazilian Portuguese?}

We now turn to the question of why non-agreeing copular sentences are systematically pancake sentences in Brazilian Portuguese. We first aim to dismiss an analysis making Brazilian Portuguese similar to French despite surface appearances. In principle, one could indeed assume an analysis in terms of leftdislocation for Brazilian Portuguese non-agreeing copular sentences as well, and posit a second silent pronominal subject with a semantics similar to the demonstrative neuter pronoun $c e$, which could also contribute to determining the semantics of the true antecedent. On that view, the nominal expression would not sit in Spec,IP, but in a higher position in the left periphery position, as schematically shown in (89).

(89) $\mathrm{DP}\left[{ }_{\mathrm{TP}}\right.$ Pred $]$

Rodrigues and Foltran $(2015,138)$, however, argue that this analysis is untenable for Brazilian Portuguese, on the basis of evidence related to different word order patterns. In particular, they point out that a $w$ h-phrase precedes the bare nominal criança 'child' in an interrogative sentence, which suggests that the bare nominal is in subject, not in topic position, see (9oa). When the bare nom-

(i) Brazilian Portuguese

Professores adjuntos me faz rir.

professor.PL.M adjunct.PL.M me make.3SG.PRS laugh

'Assistant professors make me laugh.' NОт: 'Event types involving assistant professors as theme generally make me laugh.'

This is expected given that in Brazilian Portuguese, the pancake reinterpretation of the subject is mainly induced by the adjectival copular phrase. Our feeling is that in such sentences, the first noun phrase is in a topical position, and is not selected as the external argument of the verb. We leave the problem of lack of agreement in non-copular sentences in Brazilian Portuguese for further research. 
inal occupies a left-dislocated position, as in (9ob), it precedes the $w h$-phrase. In such cases, the pronoun isso 'this' appears in the subject position (but can remain implicit, as indicated by the parenthesis), and we observe that the pancake interpretation is not available anymore.

(90) Brazilian Portuguese

a. Quando $_{i}$ que criança é divertido $t_{i}$ ? when $_{\mathrm{i}}$ that child is fun

'When is it that dealing with/speaking with children is fun?' (our translation)

b. Criança, quando ${ }_{i}$ que (isso) é divertido $t_{i}$ ? child.F.SG when $\mathrm{i}_{\mathrm{i}}$ that this is fun 'Children, when are they fun?' мот: 'When is it that dealing with/speaking with children is fun?' (our translation)

Also, we observe that often, the literal Brazilian Portuguese counterparts with the demonstrative isso of the French sentences in the previous section illustrating the meaning shifts triggered by $c e$ all turn out agrammatical, see, for instance, (91).

(91) Brazilian Portuguese

a. *(Os) passarinhos no pôr- $\varnothing$ do sol, isso *the bird.M.PL in.the.M put.NMLz in.the.M sun.M DEM é vermelho.

be.3SG.PRS red.M.SG

Intended: 'Birds-in-the-sunset, that's red.'

b. ${ }^{*}$ Os crepes, isso é saboroso.

* the pancake.M.PL DEM be.3SG.PRS delicious.M.SG Intended: '(The) pancakes, that's tasty.'

We therefore assume that in Brazilian Portuguese, pancake sentences have one subject only, standing for a non-overt semantic structure. Since the adjective agrees with this non-overt structure without agreement features, it receives default agreement, which is masculine and singular in Brazilian Portuguese.

But why does this non-overt structure systematically denote an event type? Why, in particular, can't it denote situations/states-of-affair or individual kinds, like the covert antecedent of $c e$ in French non-agreeing copular sentences? 
More concretely, why can't (11) repeated below under (92) be used to express in Brazilian Portuguese the generality that apples are red? Similarly, why are the non-agreeing copular sentences (93)-(95) all agrammatical in Brazilian Portuguese?

(92) Brazilian Portuguese

*Maçã é vermelho.

apple.F.SG be.3sG.PRS red.M.sG

Intended: 'Apples are red.'

(93) * Criança é barulhento.

child.F.SG be.3sG.PRS noisy.M.SG

Intended: 'Children are noisy.'

(94) *Panqueca é saboroso.

pancake.F.SG be.3SG.PRS delicious.M.SG

Intended: 'Pancakes are tasty.'

(95) *Gaivota no pôr- $\varnothing$ do sol é vermelho. seagull.F.SG in.the.M put.NMLZ in.the.M sun.M be.3SG.PRS red.M.SG Intended: 'Seagulls-in-the-sunset, that's red.'

We propose that the reason behind this restriction is that the semantic structure for which the subject of non-agreeing copular sentences stands for is by definition covert. But (plural and singular) bare nouns overtly denote individual kinds in Brazilian Portuguese (Müller 2002 a.o). This is true even with predicates such as noisy or tasty, which block the generic reading of indefinite or definite DPs in subject position in French. Since the bare noun can always overtly denote individual kinds in Brazilian Portuguese, agreement in gender and number is therefore required, see $(96)-(98)$ below.

(96) Brazilian Portuguese

Maçã é vermelha.

apple.F.SG is red.F.SG

'Apples are red.'

(97) Criança é barulhenta. (generic, compare with French (86)) child.F.SG be.3SG.PRS noisy.F.SG

'Children are noisy' 


\section{(98) Panqueca é}

pancake.F.SG be.3SG.PRS

saborosa.

(generic, compare with French $(87 \mathrm{~b})$ )

delicious.F.SG

'Pancakes are tasty.'

Also, we observe that in Brazilian Portuguese, modified bare nouns may overtly describe situations/states-of-affairs involving an individual denoted by the nominal expression in its literal meaning. For instance, (99) has exactly the same meaning as the one obtained through the reinterpretation triggered by $c e$ of the nominal expression in the French example (84a) (modulo the fact that (99) is generic only, while (84a) can be both episodic or generic). Thus, like (84a) built with ce, (99) does not entail that the seagulls are red by themselves.

(99) Brazilian Portuguese

Gaivota no pôr- $\varnothing$ do sol é vermelha. seagull.F.SG in.the.M put.NMLz in.the.M sun.M be.3SG.PRS red.F.SG 'Seagulls-in-the-sunset, that's (generally) red.' (situation, cp. with French $(84 b))$

In summary, it seems that in Brazilian Portuguese, bare nouns overtly have the kind-denoting or situation-denoting meaning obtained for the covert antecedent of the French pronoun $c e$. We think this is the main reason why these additional meanings are not possible in non-agreeing copular sentences in Brazilian Portuguese, and only obtain when agreement takes place. But Brazilian Portuguese bare nouns cannot denote event type by themselves. Absence of agreement is thus required and justified to trigger the event type reinterpretation via the pancake-operator and the specific semantics of predicates of personal taste. In contrast, absence of agreement is not justified for the kindand situations-interpretations, which can systematically be overtly obtained with bare nouns in Brazilian Portuguese. In French, the meaning-shifter $c e$ is in some cases needed to get the situation- and kind- interpretations which is available at the literal level in Brazilian Portuguese.

Do Pancake Sentences Exist in Other Germanic Languages?

The question of whether pancake sentences exist in Germanic languages such as English or German has to our knowledge not been investigated in detail yet. Wechsler (2013) gives en passant an example of a non-agreeing copular 
sentence with a post-copular bare NP, see (100a), which can be paraphrased as standard pancake sentences, i.e., as selling steroids is big business. (10ob) is another example, from Nicolas Dumay (p.c.).

(100) a. Steroids is big business.

b. Assistant professors is the way.

Also, non-agreeing non-copular sentences have been observed to exist in English, too, see, for instance (101) (see also examples (88a-b) in French).

(101) Scrambled eggs make(s) a good breakfast. (Lauren Ackerman, 13/o7/ 2018, Twitter)

We asked native speakers whether a semantic difference occurs between the two variants in sentences such as (101). Some of their answers are reminiscent of the differences documented between the agreeing and non-agreeing variants of adjectival copular sentences. In particular, they say that with a plural on the verb, (101) is about the eggs themselves, while with a singular, (101) states that making, preparing, etc. scrambled eggs is what makes a good breakfast. This suggests that the lack of agreement and the presence of an evaluative predicate of the right kind may also trigger the reinterpretation process of nominal expressions in subject position of non-copular sentences in English.

In general, however, pancake sentences built with a post-copular adjective rather than an NP seem much less natural in languages such as English. To begin with, we observe that pancake adjectival sentences of the French type seem not as natural in English or German, probably partly because subject dislocation is more pragmatically constrained in English than in French (Lambrecht 1987; De Cat 2002). Nevertheless, in a context satisfying the pragmatic conditions licensing left dislocation, it seems that the pronoun that used in such sentences play a very similar role to the one of $c e$ : it looks for a covert antecedent having the meaning of an event predicate or a clause (e.g., making pancakes is nice), with which the neuter pronoun agrees.

(102) ?Scrambled eggs/pancakes, that's nice.

(103) German

??Waffeln, das ist lustig.

waffle.M.PL DEM.N.SG be.3SG.PRs funny

Intended: 'Waffles, that's funny.' 
(104) ?Children, that's expensive/complicated.

(105) German

??Kinder, das ist teuer/ schwierig. child.NEUT.PL DEM.N.SG be.3SG.PRS expensive hard Intended: 'Kids, that's expensive/hard.'

In any case, English or German pancake sentences à la française are much more acceptable than their counterparts à la portugaise, which seem completely marginal in a default context, see (106)-(109).

(106) *Scrambled eggs/pancakes is fun.

(107) German

${ }^{*}$ Waffeln ist lustig.

waffle.F.PL be.3SG.PRs funny

(108) *Kids is expensive/complicated.

(109) German

${ }^{*}$ Kinder ist teuer/schwierig.

child.N.PL be.3SG.PRS expensive/hard

The reason why non-agreeing copular adjectival sentences are not grammatical in English or German is unclear to us, but we have two observations to offer. Firstly, we observe that in presence of a cardinal indefinite and an adjective inducing the collective interpretation of the cardinal, pancake sentences without left dislocation suddenly become much more acceptable in English as in German, see (110)-(111), which are quickly interpreted as meaning having /dealing with ... two cats or thirty guests is funny/hard. As we noticed in Section 4.1 through the examples (82) repeated below, even French accepts non-agreeing copular sentences with a single subject when the nominal expression contains a numeral.

(110) Two cats is funny.

(111) German

Dreizig Gäste ist schwierig.

thirty guest.M.PL be.3SG.PRS complicated

'Thirty guests is hard.' 
(82) French

Dix invités est vraiment trop difficile.

ten guest.M.PL be.3SG.PRS really too complicated.M.sG

'Ten guests is really too complicated.'

We speculate that two (related) factors explain that such sentences are much better in presence of a cardinal indefinite. Firstly, the competing agreeing form leads to a completely different interpretation, i.e., an episodic (rather than generic) statement about non-generic entities (e.g., there are two cats in the context which are funny, ten of the guests are hard). Secondly, the singular vs. plural agreement in this case is reminiscent of effects discussed in the literature on group nouns, which can show both singular and plural agreement with interpretative differences, see for instance Barker (1992); Pearson (2011); Smith (2015). For instance, the committee is old can have a reading according to which it was founded a long time ago in addition to the reading that its members are old. The plural counterpart has only the latter reading. Why would numerals trigger such an effect? Authors such as Ionin and Matushansky (2006) have argued that in general numerals combine with nouns that are semantically atomic; to the extent that plural morphology is present on the noun this lacks a semantic import. Landau (2016) puts forth an analysis of agreement patterns with numerals that builds on Wechsler and Zlatić (200o). Landau (2016, 1005) argues that numerals split the DP internal domain into two zones: above numerals, showing plural agreement, and below numerals, showing singular agreement. Singular agreement as in e.g. (82) is suggestive of an Agree relation between the predicate and the head noun, while plural agreement is suggestive of an Agree relation with the whole Quantity Phrase, assuming this is where numerals are located, cf. Borer (2005), and hence plurality leading to individual interpretation.

Secondly, we note that in striking contrast with what we observed for Brazilian Portuguese and French, the event type interpretation of the nominal expression seems (at least with some adjectives) readily available in agreeing copular sentences in English and German. Recall, for instance, that (8) and (10) were odd in Brazilian Portuguese and French, see also (112)-(114); by contrast, (115)-(118) are quite natural in English or German. This suggests that at least these adjectives manage by themselves to trigger the reinterpretation process of the nominal expression, while in contrast, this reinterpretation process has to be "signaled" by a mismatch in the agreement features in languages such as French or Brazilian Portuguese. 
(112) French

\#On fait quoi? Ben, les/des gaufres

PRN.3SG.NOM make.3SG.PRS what? well, the.PL/PA.PL waffle.F.PL sont (toujours) chouettes.

be.3PL.PRs always nice.F.PL

Intended: 'What are we baking? Well, waffles are (always) nice.'

(113) Brazilian Portuguese

\#Criança é cara.

child.F.sG be.3sG.PRs expensive.F.sG

(114) French

\#Les enfants sont chers.

the.PL child.M.PL be.3PL.PRS expensive.M.PL

(115) German

Kinder sind teuer.

child.M.PL be.3PL.PRS expensive

'Kids are expensive.'

(116) Kids are expensive.

(117) German

Was machen wir? Waffeln sind (immer) schön.

what make we? waffle.F.PL be.3PL.PRS always nice

'What should we do then? Waffles are always nice.'

(118) What are we baking? Well, pancakes are always nice.

These data are of particular interest because they suggest that the basic ingredients of one-subject-only pancake sentences are available in the grammar of English or German, but that in these languages, more contextual cues are needed to trigger the event type denoting covert structure with which the VP may agree. In favor of this view, we note that the more the subject resembles a small clause, the more the non-agreeing form is acceptable, see for instance the German contrast (119)-(120), from Florian Schäfer (p.c.). ${ }^{20}$

20 We observe something similar in French, too. In particular, with some adjectives, the dislocated nominal expression sounds sometimes somewhat better with an indefinite in 
(119) German

*Haustiere ist schwierig.

domestic animal.M.PL be.3SG.PRs hard

Intended: 'Having/caring of ... domestic animals is hard.'

(120) Haustiere in einer kleine Wohnung ist

domestic animal.M.PL in a small apartment be.3SG.PRS schwierig.

hard

'Having/caring of ... domestic animals in a small apartment is hard.'

This, we suggest, again confirms that it is well and truly possible to have nonagreeing copular adjectival sentences with an event type interpretation for nominal expressions in languages such as German, too, provided that the context helps to get rid of the individual-denoting interpretation and induce the event type-denoting covert structure, with which the verb may agree.

\section{Acknowledgements}

We thank our anonymous reviewers for valuable comments on previous versions of this paper. We are also very grateful to Christopher Piñón for very helpful and constructive feedback on the semantic analysis, Giorgos Spathas for his insightful remarks on a previous draft, as well as to audiences at SLE Workshop on Bare Nouns vs. Partitive Articles in September 2017 in Zurich, at Humboldt-Universität zu Berlin, at the University of Leipzig and at 3 rd EISSI in Florianopolis in 2018 for their comments. We also thank Nicolas Dumay and Florian Schäfer for discussions on the data, and Tabea Ihsane for her editorial work. Usual disclaimers apply. A. Alexiadou and J. Carvalho's research was sup-

presence of a modifier making the subject more similar to a clause, compare (i) and (ii) below. Definite dislocated nominal expressions are in contrast always acceptable.

(i) French

(?)Des enfants, c'est compliqué.

PA.PL child.M.PL DEM=be.3SG.PRS complicated.M.SG '(The) kids, that's complicated.'

(ii) Des enfants qui mangent des spaghettis, c'est PA.PL child.M.PL who eat.3PL.PRS PA.PL spaghetti.M.PL DEM=be.3SG.PRS compliqué. complicated.M.sG

'Kids eating spaghettis, that's complicated.' 
ported by HU-USP 6/2016 project $A$ cross-linguistic investigation of the role of number and gender in nominal expression. F. Martin's research was supported by the DFG award AL 554/8-1 (Leibniz-Preis 2014) to A. Alexiadou.

\section{References}

Attal, Pierre. 1976. "A propos de l'indéfini des: Problèmes de représentation sémantique." Le Français moderne 44, no. 2:126-142.

Bhatt, Rajesh, and Roumyana Pancheva. 1997. Implicit arguments. Manuscript, U. Texas and Usc.

Barker, Chris. 1992. "Group Terms in English: Representing Groups as Atoms." Journal of Semantics 9: 69-93.

Borer, Hagit. 2005. In name only. Oxford: Oxford University Press.

Bylinina, Lisa. 2014. "The Grammar of Standards. Judge-dependence, Purpose-relativity and Comparison Classes in Degree Constructions." Doctoral Diss., LOT, Utrecht University.

Bylinina, Lisa. 2017. "Judge-dependence in degree constructions." Journal of Semantics 34, no. 2: 291-331.

Cadiot. Pierre. 1988. "De quoi ça parle? A propos de la référence de ça, pronom-sujet." Le Français moderne 65: 174-192.

Carlier, Anne. 1996. "Les gosses, ça se lève tôt le matin'. L' interprétation générique du syntagme nominal disloqué au moyen de ce ou ça." French Language Studies 6: 133162.

Danon, Gabi. 2012. "Nothing to agree on: Non-agreeing subjects of copular clauses in Hebrew." Acta Linguistica Hungarica 59, no. 1-2: 85-108.

De Cat, Cécile. 2002. "French Dislocation." Doctoral Diss., York University.

De Conto, Luana. 2016. "The situation reading in copular sentences with agreement mismatch: a derivational problem." Caderno de Squibs: Temas em estudos formais da linguagem 2, no. 1: 31-40.

De Conto, Luana. 2018. Tese é complicado: A leitura de situação em sentenças copulares com concordância não marcada. Doctoral Diss., Federal University of Paraná.

Dobrovie-Sorin, Carmen, and Claire Beyssade. 2012. Redefining Indefinites. Berlin: Springer.

Epstein, Samuel. 1984. "Quantifier -pro and the LF representation of $\mathrm{PRO}_{\text {arb }}$. Linguistic Inquiry 15, no. 3: 499-505.

Furukawa, Naoyo. 1989. "Le SN générique et les pronoms ça/ils: sur le statut référentiel des SN génériques." Modèles linguistiques XI, no. 2: 37-57.

Gerards, David Paul, and Elisabeth Stark. This volume. "Why 'Partitive Articles' Do Not Exist in (Old) Spanish." 
Greenberg, Yael. 2008. Predication and equation in Hebrew (non-pseudocleft) copular sentences. In Current issues in generative Hebrew linguistics, edited by Sharon Armon-Lotem, Gabi Danon and Susan Rothstein, 1, 161-196. Amsterdam: John Benjamins.

Giusti, Giuliana. This volume. "A Protocol for Indefinite Determiners in Italian and Italo-Romance."

Hacquard, Valentine. 2006. "Aspects of modality." PhD Diss., Massachusetts Institute of Technology.

Heller, Daphna. 1999. "The syntax and semantics of specificational pseudoclefts in Hebrew." MA. Thesis, Tel Aviv University.

Josefsson, Gunlög. 2014. "Pancake sentences and the semanticization of formal gender in Mainland Scandinavian." Language Sciences 43: 62-76.

Ihsane, Tabea. This volume. "Telicity, Specificity, and Complements with a 'Partitive Article' in French."

Ionin, Tania, and Ora Matushansky. 20o6. "The composition of complex cardinals." Journal of Semantics 23: 315-36o.

Kertz, Laura. 2009. "The argument structure of evaluative adjectives: A case of pseudoraising." In Movement theory of control, edited by Norbert Hornstein and Maria Polinsky, 269-298. Amsterdam: John Benjamins.

Lambrecht, Knud. 1987. "On the status of svo sentences in French discourse." In Coherence and Structure in Discourse, edited by Russell Tomlin, 217-261. Amsterdam:John Benjamins.

Landau, Idan. 2009. "Saturation and reification in adjectival diathesis." Journal of Linguistics 45: 315-361.

Landau, Idan. 2013. Control in generative grammar: A research companion. Cambridge: Cambridge University Press.

Landau, Idan. 2016. "DP-internal Semantic Agreement: A configurational analysis." Natural Language and Linguistic Theory 34: 975-1020.

Lasersohn, Peter. 2005. "Context dependence, disagreement, and predicates of personal taste." Linguistics and philosophy 28, no. 6: 643-686.

Martin, Fabienne. 20og. Les prédicats statifs. Etude sémantique et pragmatique. Paris/ Bruxelles: de Boeck/Duculot.

Martin, Fabienne. 2014. "Restrictive vs. nonrestrictive modification and evaluative predicates." Lingua 149, 34-54.

Müller, Ana. 2002. "The semantics of generic quantification in Brazilian Portuguese." Probus 14, no. 2: 279-298.

Parsons, Terence. 199o. Events in the semantics of English. A study in subatomic semantics. Cambridge, MA: MIT Press.

Pearson, Hazel. 2011. "A new semantics for group nouns." In Proceedings of the 28th West Coast Conference on Formal Linguistics, edited by Mary Washburn, Kather- 
ine McKinney-Bock, Erika Varis, Ann Sawyer and Barbara Tomaszewicz. 16o-168. Somerville, MA: Cascadilla Proceedings Project.

Pearson, Hazel. 2013. "A judge-free semantics for predicates of personal taste." Journal of Semantics 30:103-154.

Piñón, Christopher. 2016. More generous behavior. Invited talk given to WAASAP 3, Lille, June 2016.

Pustejovsky, James. 1995. The generative lexicon. Cambridge, MA: MIT Press.

Ramchand, Gillian. 2018. "Alternating adjectives." The Linguistic Review 35, no. 2: 283306.

Reed, Lisa. 1997. "Pronominalized Aspect." Studia Linguistica 51, no. 2:121-153.

Rodrigues, Patricia, and Maria José Foltran. 2015. "Small nominals in Brazilian Portuguese copular constructions." Journal of Portuguese Linguistics 14, no. 1: 129-147.

Roy, Isabelle, and Ur Shlonsky. 2019. "Aspects of the syntax of $c e$ in French copular sentences." In The Grammar of Copulas Across Languages, edited by María Arche, Antonio Fábregas, and Rafael Marín. 153-169. Oxford: Oxford University Press.

Schurr, Hagay. This volume. "Bound To Be? Bare and Partitive-Marked Noun Phrases in Romance Languages and the Emergence of Prominence-Conditioned Patterns."

Smith, Peter. 2015. "Feature mismatches: consequences for syntax, morphology and semantics.” PhD Diss., University of Connecticut.

Stark, Elisabeth, and David Paul Gerards. This volume. "Partitive Articles' in Aosta Valley Francoprovençal—Old Questions and New Data."

Stephenson, Tamina. 2007. "Judge dependence, epistemic modals, and predicates of personal taste." Linguistics and Philosophy 30, no. 4: 487-525.

Strobel, Thomas, and Elvira Glaser. This volume. "The Rise and Fall of Partitive Markers in Some Germanic varieties."

Wechsler, Stephen. 2013. "The structure of Swedish pancakes." In The Core and the Periphery:Data-Driven Perspectives on Syntax Inspired by Ivan A. Sag, edited by Philip Hofmeister and Elizabeth Norcliffe. 71-98. Stanford: CSLI Publications.

Wechsler, Stephen, and Larisa Zlatić. 20oo. "A theory of agreement and its application to Serbo-croatian." Language 76, no. 4: 799-832. 